\title{
Hernia interna de divertículo de Meckel como causa de obstrucción intestinal en un senescente*
}

\author{
Dr. MARIO ESTRELLA R. ${ }^{1}$, Ints. JOSE BERNAL R. ${ }^{2}$, LORETO FUENZALIDA C. ${ }^{2}$
}

Servicio de Cirugía, Hospital San Martín, Quillota, Chile.

2 Interno Medicina Universidad de Santiago, Chile.

\begin{abstract}
\section{Internal hernia of Meckel diverticulum in elderly patient}

Meckel Diverticulum is the most frequent gastrointestinal congenital anomaly. General population incidence is $2 \%$. Complications develop in 4 to $30 \%$ of the cases, where over $50 \%$ present during the first decade. This high incidence progressively decreases to cero in elderly patients, as some authors propose. Bowel obstruction, the most prevalent complication in adults, occurs by different mechanisms; however there is no available publication that mentions an internal hernia of Meckel Diverticulum through colonic mesentery. Meckel Diverticulum complications are rare in elderly patients; moreover an internal hernia generating bowel obstruction is even more infrequent. We present a 75-year-old male patient with bowel obstruction produced by a Meckel Diverticulum herniated through colonic mesentery.
\end{abstract}

Key words: Meckel Diverticulum, bowel obstruction, internal hernia.

\section{Resumen}

El divertículo de Meckel (DM), es la anomalía congénita más frecuente del tracto gastrointestinal. Su incidencia en población general es de $2 \%$. Las complicaciones se presentan entre 4-30\% de casos. Más de $50 \%$ ocurren en la primera década de vida, disminuyendo drásticamente con la edad, llegando a cero en adultos mayores (AM) según algunos autores. La obstrucción intestinal (OI), complicación más frecuente en adultos, tiene distintos mecanismos patogénicos; sin embargo, no hay literatura disponible que mencione la hernia interna del DM en el mesenterio colónico. La complicación del DM es infrecuente en el AM, siendo más infrecuente aún, la hernia del DM en el mesenterio colónico como causa de una OI. Presentamos un paciente masculino, 75 años con obstrucción intestinal secundaria a un DM herniado en mesenterio del colon ascendente.

Palabras clave: Divertículo de Meckel, obstrucción intestinal, hernia interna.

\footnotetext{
*Recibido el 7 de Agosto de 2008 y aceptado para publicación el 9 de Octubre de 2008.

Correspondencia: Dr. Mario Estrella R.

Av. Concepción 1050, Quillota, Chile.

E-mail: naibok@gmail.com
} 


\section{Introducción}

Descrito por primera vez en 1598 por el cirujano alemán Wilhelm Fabricius Hildanus, y luego por Johann Friedrich Meckel en 1808, quien publicó de forma más detallada el divertículo que hoy lleva su nombre ${ }^{1,2}$.

El divertículo de Meckel (DM), es un divertículo intestinal verdadero ${ }^{3}$, resultante de la obliteración incompleta del conducto onfalomesentérico durante la $6^{\mathrm{a}}-8^{\mathrm{a}}$ semana del desarrollo intrauterino ${ }^{1}$. Corresponde a la anomalía congénita más frecuente del tracto gastrointestinal ${ }^{4}$. Su incidencia en la población general es de $2 \%{ }^{2,5}$, con un rango entre $0,3 \%$ y $4 \%{ }^{5}$, siendo más frecuente en el sexo masculino.

Contiene todas las capas normales de la pared intestinal y aproximadamente en un 50-60\% presenta tejido ectópico, del cual el $62 \%$ corresponde a mucosa gástrica, pudiendo presentar además, tejido pancreático, mucosa colónica, endometriosis o tejido hepatobiliar, entre otros ${ }^{6}$. Generalmente, mide entre 1 y $10 \mathrm{~cm}$ y siempre está ubicado en el borde antimesentérico del íleon, a una distancia entre 45$100 \mathrm{~cm}$ (promedio 67,5 cm), desde la válvula ileocecal ${ }^{3}$.

La relevancia de la presencia de un DM, radica en la posibilidad de desarrollar complicaciones; éstas se presentan en 4 a $30 \%$ de las personas afectadas, siendo 2 a 3 veces más frecuentes en el sexo masculino y destacan entre ellas la hemorragia, inflamación y obstrucción Intestinal. Las complicaciones pueden presentarse en cualquier grupo etario, siendo más frecuentes en la primera década de la vida $(>50 \%)^{3,4,7}$, disminuyendo drásticamente con la edad ${ }^{5,8}$, e incluso algunos autores señalan que el riesgo baja a cero en la tercera edad ${ }^{2,9}$.

En la población adulta, la complicación más frecuente es la obstrucción intestinal ${ }^{2}$. Se han planteado distintos mecanismos que influyen en su desarrollo, sin embargo, no hay literatura, nacional ni internacional, que mencione la hernia interna del Divertículo de Meckel en el mesenterio colónico, como causa de esta complicación.

A continuación se presenta el caso clínico de un paciente adulto mayor con divertículo de Meckel, complicado con una hernia interna.

\section{Caso clínico}

Paciente masculino de 75 años de edad, sin antecedentes mórbidos de significancia, admitido en el Servicio de Urgencia del Hospital San Martín de Quillota, con diagnóstico de obstrucción intestinal. Refiere historia de 24 horas de evolución caracteri- zado por distensión y dolor abdominal cólico, con ausencia de expulsión de deposiciones y gases por ano. Al ingreso, el paciente se presenta en regular condición general, hidratado, presión arterial 136/ 69 , frecuencia cardíaca de 80 latidos/minutos y temperatura axilar de $36,3^{\circ}$ Celsius.

Al examen físico, destaca abdomen distendido, depresible, sensible difusamente, timpánico y ruidos hidroaéreos disminuidos. Al tacto rectal, se consigna ampolla vacía y tonicidad esfinteriana conservada. Se instala sonda nasogástrica, obteniéndose contenido fecaloideo.

En los exámenes de ingreso destaca leucocitosis de 12,200 x mm 3 , PCR $227 \mathrm{mg} / \mathrm{dl}$ y glicemia $125 \mathrm{mg} / \mathrm{dl}$; hematocrito, hemoglobina, amilasa, electrolitos plasmáticos, función renal y pruebas de coagulación, dentro de límites normales. La radiografía de abdomen simple, demostró niveles hidroaéreos y dilatación intestinal (Figura 1).

El abordaje quirúrgico se realizó a través de una laparotomía media supra e infra umbilical, evidenciándose dilatación importante de intestino delgado y un divertículo de Meckel a $50 \mathrm{~cm}$ desde la válvula ileocecal, introducido en un ojal a nivel del mesenterio de colon ascendente. Con maniobras romas y digitales se logró liberar dicho divertículo, apreciando sobre su base estigmas de sufrimiento. Se realiza resección en cuña del divertículo y se sutura con dexon ${ }^{\circledR} 3 / 0$ en un solo plano. Resto del intestino sin otros hallazgos. La pared abdominal

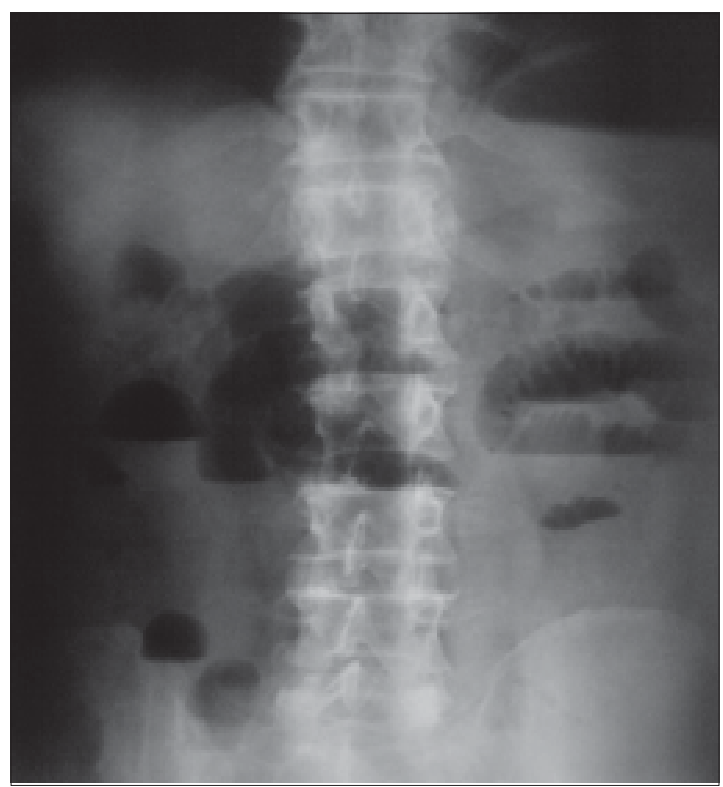

Figura 1. Radiografía abdomen simple de pie, con niveles hidroaéreos y dilatación de intestino delgado. 
se cerró por planos y no se dejaron drenajes. El paciente evoluciona favorablemente y es dado de alta al séptimo día, en buenas condiciones.

En el estudio anatomopatológico, se describe un divertículo de Meckel de 2,2 cm de largo y $2 \mathrm{~cm}$ de diámetro. Sin presencia de mucosa heterotópica en su interior.

\section{Discusión}

El DM que presentaba nuestro paciente tenía una longitud de $2,2 \mathrm{~cm}$ y se encontraba a $50 \mathrm{~cm}$ de la válvula ileocecal, lo cual coincide con las descripciones clásicas de la literatura. No contenía mucosa gástrica, tejido heterotópico más frecuente, explicando la ausencia de complicaciones previas, como hemorragia o anemia crónica.

Entre las distintas complicaciones de un DM, se encuentran: obstrucción intestinal 36,5\%, intususcepción $13,7 \%$, inflamación $12,7 \%$, hemorragia $11,8 \%$, perforación $7,3 \%$, componente de un saco herniario $4,7 \%$; desarrollo de neoplasia $3,2 \%$ y fístula umbilical $1,7 \%{ }^{3}$.

En los niños la complicación más frecuente y peligrosa es la hemorragia, que se asocia a la presencia de mucosa gástrica heterotópica productora de acido clorhídrico capaz de ulcerar el intestino normal adyacente ${ }^{3,10}$. En la población adulta, la complicación más frecuente es la obstrucción intestinal, representado entre $26 \%$ y $53 \%{ }^{2}$. Esta ocurre por distintos mecanismos etiopatogénicos, entre los cuales se encuentran: intususcepción, el más fre-

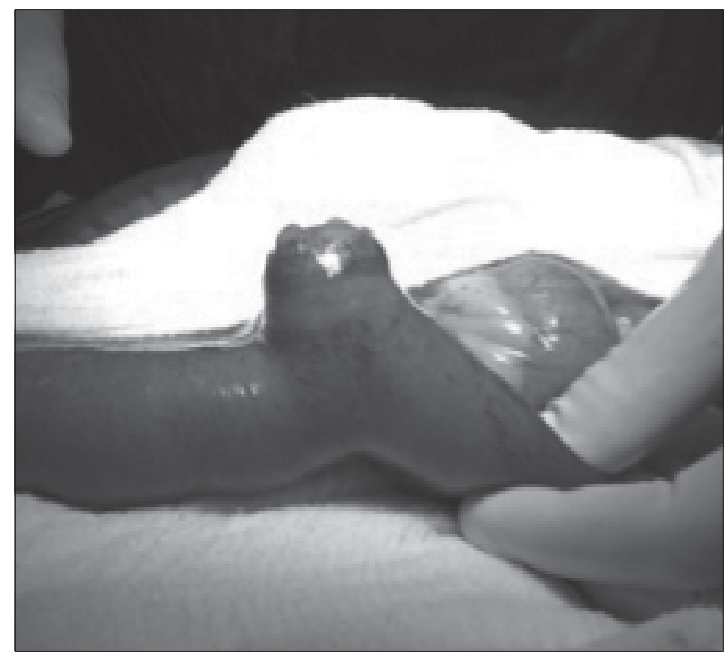

Figura 2. Divertículo de Meckel con signos de estrangulación e inflamación peridiverticular. cuente; hernia interna al atraparse una asa intestinal normal entre el mesenterio y el mesodiverticular; hernia de Littré, adherencias por inflamación o un vólvulo diverticular, entre otras ${ }^{8}$.

No encontramos descrita en la literatura disponible, como otro mecanismo de obstrucción intestinal, la herniación del DM en el mesenterio del colon ascendente, conformando una hernia interna. Si bien la estrangulación del DM, no afecta de forma directa la luz intestinal, se explica la obstrucción por la inflamación peridiverticular, manifestada con los signos de estrangulación diverticular (Figuras 2 y 3$)$.

En un estudio realizado por John y cols ${ }^{1}$, que describe la experiencia de la Clínica Mayo respecto al divertículo de Meckel, entre 1950 y 2002 con un total de 1.476 pacientes, destaca que el $16 \%$ fue un DM sintomático y de ellos el $76 \%$ eran adultos, considerados como aquellos los mayores de 11 años. Entre este último grupo, se encontró que la frecuencia del DM sintomático disminuye con la edad y se reportan aproximadamente 60 pacientes $(4 \%$ del total) con edad mayor a 60 años. En este estudio, que recopila información de más de 50 años, se mencionan sólo 2 casos de hernia incarcerada, aunque no hacen referencia al tipo de hernia, Menos de $10 \%$ de todos los divertículos de Meckel sintomáticos se diagnostican en el preoperatorio ${ }^{8}$. En nuestro paciente el diagnóstico preoperatorio fue de síndrome de obstrucción intestinal, y no se planteó la presencia de un DM, debido a la edad del paciente y a la ausencia de antecedentes como hemorragia y anemia crónica.

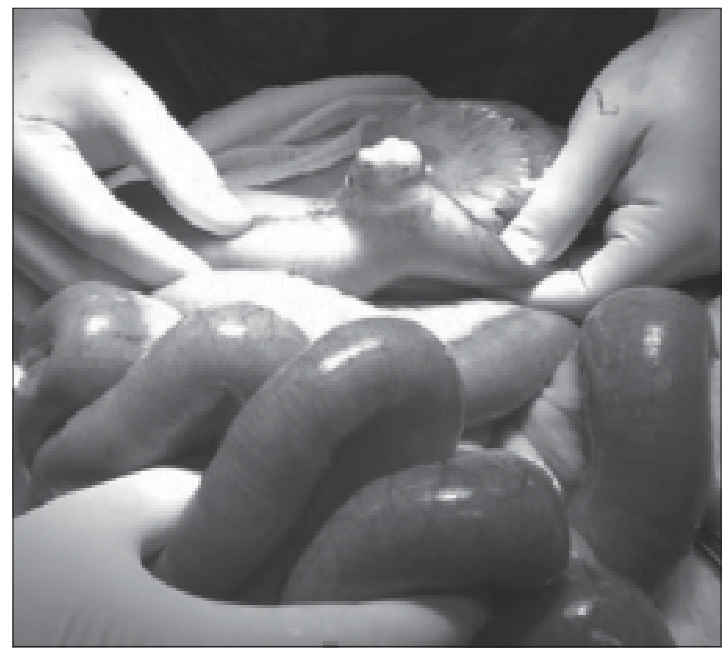

Figura 3. Divertículo de Meckel con halo isquémico y dilatación intestinal. 


\section{Conclusión}

La complicación del DM, es un hecho infrecuente en el adulto mayor, no existiendo datos exactos en la literatura disponible, respecto a su incidencia o tipo de complicación.

\section{Referencias}

1. Park J, Wolff B, Tollefson M, Walsh E, Larson D. The Mayo Clinic Experience with 1476 Patients (1950-2002). Ann Surg 2005; 241: 529-533.

2. Dumper J, Mackenzie S, Mitchell P, Sutherland F, Lynn M. Complications of Meckel's diverticula in adults. Can J Surg 2006; 49: 353-358.

3. Yahchouchy E, Marano A, Etienne J, Fingerhurt A. Meckel's diverticulum. J Am Coll Surg 2001; 192: 658-662.

4. Piñero A, Martínez E, Canteras M, Castellanos G,
Rodríguez JM, Parrilla P. Complicaciones, diagnóstico y tratamiento del divertículo de Meckel. Cir Esp 2001; 70: 286-290.

5. Beltran M, Larenas R, Almonacid J. Vólvulo de divertículo de Meckel: una complicación inusual. Rev Chil Cir 2006; 58: 50-53.

6. Artigas V, Calabuig R, Badia F. Meckel's diverticulum: value of ectopic tissue. Am J Surg 1986; 151: 631634.

7. Campus Vilata B. El Divertículo de Meckel. Diagnóstico y tratamiento de sus complicaciones. Rev Cir Esp 1984; 3: 456-459.

8. Massotto H, Zúñiga L. Vólvulo intestinal secundario a Divertículo de Meckel. Acta Médica Costarricense, 2003; 45: 175-177.

9. Zúniga G. Divertículo de Meckel, Revisión bibliográfica. Rev Med Hond 1990; 58: 227-229.

10. Schmidt C, Brown LM, Klomp HJ, Henne-Bruns D. Perforated Meckel's diverticulum. Surgery 2001; 129: 643-644. 